\title{
Erratum
}

Yasser S. Mostafa, Saad A. Alamri, Mohamed Hashem, Nivien A. Nafady, Kamal A. M. Abo-Elyousr, Zakaria A. Mohamed

\section{Erratum to "Thermostable cellulase biosynthesis from Paenibacillus alvei and its utilization in lactic acid production by simultaneous saccharification and fermentation"}

https://doi.org/10.1515/biol-2020-0104

received October 16, 2020; accepted October 16, 2020

In the published article "Mostafa YS, Alamri SA, Hashem M, Nafady NA, Abo-Elyousr KAM, Mohamed ZA. Thermostable cellulase biosynthesis from Paenibacillus alvei and its utilization in lactic acid production by simultaneous saccharification and fermentation. Open Life Sci. 2020;15:185-97. doi: 10.1515/biol-2020-0019” the affiliations of authors Kamal A. M. Abo-Elyousr and Zakaria A. Mohamed are incorrect.
The correct affiliations of Kamal A. M. Abo-Elyousr and Zakaria A. Mohamed are as follows:

Kamal A. M. Abo-Elyousr, Assiut University, Faculty of Agriculture, Plant pathology Department, Assiut, Egypt; King Abdulaziz University, Faculty of Meteorology, Environmental and Arid Land Agriculture, Department of Arid Land Agriculture, Saudi Arabia

Zakaria A. Mohamed, Department of Botany \& Microbiology, Faculty of Science, Sohag University, Sohag, 82524, Egypt 